\title{
RESUMO
}

ISSN Digital: 2316-3828

ISSN Impresso: 2316-333X

DOI: 10.17564/2316-3828.2019v7n3p155-168

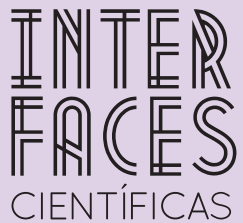

CIENTÍFICAS

\section{ENSINO TÉCNICO PROFISSIONALIZANTE: CAMINHOS PERCORRIDOS EM TERRITÓRIO BRASILEIRO}

PROFESSIONALIZING TECHNICAL TEACHING: ROADS PERCURRED IN BRAZILIAN TERRITORY

EDUCACIÓN TÉCNICO PROFESIONAL: CAMINOS RECORRIDOS EN TERRITORIO BRASILEÑO
Andrea Karla Ferreira Nunes

Emerson dos Santos LIma²
Este artigo tem o objetivo de evidenciar a importância da educação a distância na formação técnica profissionalizante e pretende, especificamente, traçar o caminho do ensino técnico profissionalizante, abordando fatos, desde as primeiras leis até chegar na educação a distância, também apresentar dados que comprovam as contribuições da educação a distância (EAD) para o ensino técnico profissionalizante. Para tanto, foi feita uma busca em bibliografias pertinentes, que o classifica como resultado de uma pesquisa bibliográfica; além de consultas em leis e decretos que abordam sobre a temática aqui abordada, dando a este artigo o viés da pesquisa documental. Com base nos dados coletados, por meio dos documentos e bibliografias consultados, conclui-se que a tornou-se grande aliada no processo de formação técnica dos estudantes brasileiros e altamente relevante para o avanço dos cursos técnicos profissionalizantes, visto que cresce a oferta e a procura por cursos nesta modalidade.

\section{PALAVRAS-CHAVE}

Cursos Profissionalizantes. Educação a Distância. Formação Técnica. Leis. 


\section{ABSTRACT}

This article aims to evidence the importance of distance education in technical vocational training, and specifically intends to chart the way of vocational technical education, addressing facts, from the first laws to reach distance education, and present data that prove the EAD's contributions to vocational technical education. Therefore, a search was made in pertinent bibliographies, which classified it as the result of a bibliographical research; in addition to consultations in laws and decrees that deal with the subject matter addressed here, giving this article the bias of documentary research. Based on the collected data, through documents and bibliographies consulates, it is concluded that distance education has become a great ally in the process of technical training of Brazilian students and highly relevant for the advancement of vocational technical courses, as there is a growing supply and the search for courses in this modality.

\section{KEYWORDS}

Professional Courses. Distance Education. Technical Graduation. Laws.

\section{RESUMEN}

Este artículo tiene el objetivo de evidenciar la importancia de la educación a distancia en la formación técnica profesional, y busca, específicamente, preparar el camino de la enseñanza técnica profesional. Para eso, se realizó una búsqueda en bibliografías pertinentes, que lo califica como resultado de una investigación bibliográfica; además de consultas en leyes y decretos que abordan sobre el tema tratado acá, dándole el sesgo de la búsqueda documental. Basado en los datos colectados, a través de los documentos y bibliografías consultados, se concluye que la educación a distancia es fuerte aliada en proceso de formación técnica de los estudiantes brasileños y muy relevante para el avance de los cursos técnicos profesionales, visto que crece la oferta y la demanda por cursos en esta modalidad.

\section{PALABRAS CLAVE}

Cursos Profesionales. Educación a Distancia. Formación Técnica. Leyes. 


\section{INTRODUÇ̧̃̃o}

A historiografia da educação brasileira considera, como o marco da educação escolar no Brasil, o ano de 1549. Esse período, março de 1549, precisamente, foi marcado pela chegada dos primeiros jesuítas ao País, que, tinham o objetivo de levar a fé católica aos moradores da região com terras recém-descobertas à época, os índios.

Por entenderem que não seria possível catequisar os índios, sem que eles soubessem ler e escrever, os jesuítas iniciaram, então, um trabalho educativo, dando início ao processo educacional brasileiro. Entretanto, atualmente, os objetivos que se espera alcançar com a educação são os mais diversos possíveis, podendo ser apenas por uma exigência familiar à qualificação para o mercado de trabalho.

Nesse sentido, há pessoas que estudam para conseguir melhores empregos, para isso, pensam no nível superior, a fim de assumirem um perfil profissional específico. Outros, no entanto, optam pelo curso técnico profissionalizante, pois precisam de uma formação específica e em menor espaço de tempo, pois querem se inserir no mercado de trabalho o mais rápido possível.

No que se refere à educação técnica profissionalizante, as pesquisas mostram que a procura por esse tipo de qualificação tem aumentado significativamente. Nesse sentido, segundo o Instituto Brasileiro de Geografia e Estatística (IBGE), até 2014, 24,7 milhões de pessoas já tinham feito, ou ainda estavam fazendo, um curso técnico.

É importante evidenciar que a modalidade de ensino a distância tem contribuído para o crescimento desse gênero educacional. Isso se comprova nos dados do Censo 2017, da Associação Brasileira de Ensino a Distância (ABED), que divulgou que a procura por cursos técnicos na modalidade EAD expandiu 213\%, em 11 anos, subindo de 66 ofertas de cursos em 2006, para 219 em 2017.

Diante disso, ressalta-se que o objetivo deste artigo é evidenciar a importância da educação a distância na formação técnica profissionalizante. Especificamente, busca-se traçar o caminho do ensino técnico profissionalizante, abordando fatos desde as primeiras Leis até chegar na educação a distância e apresentar dados que comprovam as contribuições da EAD para o ensino técnico profissionalizante.

\section{ENSINO TÉCNICO PROFISSIONALIZANTE: DAS PRIMEIRAS LEIS À EDUCAÇ̃̃O A DISTÂNCIA}

A primeira notícia com relação à necessidade de um apoio do governo acerca da educação profissional no Brasil se deu, segundo o Parecer 16, aprovado em 5 de outubro de 1999; em 1809, quando o Príncipe Regente, futuro D. João VI, criou o Colégio das Fábricas², logo após a suspensão da proibição de funcionamento das indústrias manufatureiras em terras brasileiras.

A educação profissional, nessa época, buscava amparar os órfãos e as pessoas que não tinham boas condições sociais, isto é, pessoas pobres. Entretanto, é importante ressaltar que o objetivo des-

2 Considerado o primeiro estabelecimento instalado pelo poder público, com o objetivo de atender à educação dos artistas e aprendizes vindos de Portugal (GARCIA, 2000)

Interfaces Científicas • Aracaju • V.7 • N.3 • p. 155 - 168 • Abril/Maio/Junho - 2019 
se ensino profissionalizante era para que essas pessoas não terminassem praticando ações que fossem de encontro aos bons costumes da época.

Em 1906 o ensino profissional passou aos cuidados do Ministério da Agricultura, Indústria e Comércio, robustecendo uma política de incentivo ao desenvolvimento do ensino industrial, comercial e agrícola. Já na década de 1920, a Câmara dos Deputados engendrou debates sobre a expansão do ensino profissional. Em 1924, um grupo de ativistas criou a Associação Brasileira de Educação (ABE), que se tornou importante incentivadora do movimento renovador da educação brasileira, que existe até hoje e continua agindo em favor da educação.

Segundo o Parecer 16/99, o ensino secundário, o normal e o superior, chamados hoje como ensinos fundamental, médio e superior; eram de competência do Ministério da Justiça e dos Negócios Interiores, e o ensino profissional, como já citado, era subordinado ao Ministério da Agricultura, Indústria e Comércio. Segundo esse Parecer,

[...] o objetivo do ensino secundário e normal era o de "formar as elites condutoras do país' e o objetivo do ensino profissional era o de oferecer 'formação adequada aos filhos dos operários, aos desvalidos da sorte e aos menos afortunados, aqueles que necessitam ingressar precocemente na força de trabalho". (BRASIL, 1999, p. 6).

Essa prática perdurou por muito tempo, uma vez que estavam sendo mantidos os interesses, como o próprio documento nomeia, das elites condutoras. Uma mudança em relação a isso ocorreu somente na década de 1950, dos idos de 1900, quando se começou a ser permitida a equivalência entre os estudos.

Entretanto, é preciso enfatizar que essa mudança foi apenas parcial, pois somente com a Lei de Diretrizes e Bases da Educação (LDB), Lei 4.024, de 20 de dezembro de 1961, é que foi plenamente permitida a equivalência entre todos os cursos de mesmo nível. Esta lei nivelou o ensino profissional, assim, todos os ramos e modalidades de ensino passaram a ser equivalentes.

A partir desse momento a educação profissional deixa de ser de acesso exclusivo de instituições privadas e passa, também, ser facultada ao sistema público de ensino, embora ele não tenha recebido o apoio necessário para oferecer cursos com a qualidade compatível às exigências do país.

Diante disso, Moura, Garcia e Ramos (2007, p. 6) afirmam que:

O documento do MEC já apontava naquele momento a perspectiva de integração das políticas para o ensino médio e para a educação profissional, tendo como objetivo o aumento da escolarização e a melhoria da qualidade da formação do jovem e o adulto trabalhador.

Uma vez que o Ministério da Educação estabelecia a proposta de integração do ensino, em 1971, ainda sob o regime da Ditadura Militar no Brasil, houve uma reforma na educação básica, promovida pela Lei 5.692, de 11 de agosto de 1971, conhecida como a Lei da Reforma do Ensino de $1^{\circ}$ e $2^{\circ}$ Graus, cujo objetivo era a estruturação do ensino de cunho profissionalizante.

Tratava-se de um aspecto relevante, porém polêmico, a profissionalização nessa etapa do processo de ensino. Vale ressaltar que essa lei foi um tanto contraditória, pois foi publicada sem emendas, 
revogando mais de 50 artigos da lei anterior, a Lei 4.024, de 20 de dezembro de 1961.

O governo da época, segundo Moura, Garcia e Ramos (2007), mesmo sob o Regime da Ditadura Militar, vivia elevados índices de aceitação popular, e, por conta dessa aceitação, sobretudo na tentativa de manter-se nesse nível de aprovação, se propunha a dar respostas à população, por conta disso, desenvolveu um projeto centrado na nova fase de industrialização subalterna, que ficou conhecido como o milagre brasileiro. "Esse milagre demandava por mão-de-obra qualificada (técnicos de nível médio) para atender a tal crescimento” (MOURA; GARCIA; RAMOS, 2007, p. 14).

Após o regime ditatorial, essa prática educativa perdurou, chegando até ao final da década de 1990, onde o governo proporcionava formação técnica profissionalizante aos alunos matriculados na rede estadual de educação e, consequentemente, assegurava a inserção desses alunos no mercado de trabalho, que estava em plena expansão. Diante dessa realidade, a escola passou a ser vista como um espaço de grande importância para o mercado de trabalho.

Isso se comprova no pensamento de Mimesse (2007, p. 106), quando afirma que “[...] a profissionalização do ensino encontrou espaço, com a criação e o desenvolvimento de um modelo de currículo, mais adequado às inovações, mais ágil, mais prático, reduzindo alguns dos conteúdos teóricos considerados".

No entanto, um dos problemas enfrentados por alunos dessas escolas é que essa modalidade de escolarização comprometia a formação geral do educando, uma vez que, apenas na primeira série do antigo $1^{\circ} \mathrm{grau}$, estudavam-se conteúdos gerais, e nas segunda e terceira séries estudavam-se apenas conteúdos exclusivos à área de conhecimento do curso profissionalizante ao qual o aluno estava matriculado.

Além de representar uma perda em relação aos conteúdos gerais das séries finais do $2^{\circ} \mathrm{grau}$, também denotava uma fatídica reprovação no processo seletivo vestibular da época, uma vez que, independente da área à qual se inscrevesse o candidato ao vestibular, o edital do processo cobrava os conteúdos de todas as disciplinas obrigatórias ao ensino do $2^{\circ}$ grau, à época chamado de currículos propedêuticos.

Por conta disso, era praticamente impossível para o estudante, que cursasse o $2^{\circ}$ grau técnico profissionalizante, conseguir passar em vestibulares no país, pois, para os cursos oferecidos pelas Instituições de Ensino Superior (IES), sem exceção, eram cobrados os conteúdos programáticos dos $1^{\circ}, 2^{\circ}$ e $3^{\circ}$ anos do antigo $2^{\circ}$ grau.

Por entenderem que a formação adequada para seus filhos passava pelo ensino propedêutico, muitos pais de classe média começaram a retirar seus filhos de escolas públicas e os matriculavam em instituições particulares, pois entendiam que este era o melhor caminho que conduziria os alunos à graduação.

Devido à fuga da classe média para o ensino particular, do final da década de 1980 e a primeira metade da década de 1990, essa profissionalização obrigatória ao ensino médio vai perdendo força, e, com a aprovação, em 1996, no Congresso Nacional, da nova Lei de Diretrizes e Bases (LDB), Lei 9.394, de 20 de dezembro de 1996, o ensino profissionalizante do $2^{\circ}$ grau fica ainda mais fraco. “[...] já quase não há mais $2^{\circ}$ grau profissionalizante no país, exceto nas Escolas Técnicas Federais (ETF), Escolas Agrotécnicas Federais (EAT) e em poucos sistemas estaduais de ensino" (MOURA; GARCIA; RAMOS, 2007, p. 15).

A Lei 9.394, a chamada nova LDB, em seu artigo 21, deixa claro que a educação escolar está composta de dois níveis, sendo que o primeiro é a educação básica, formada pela educação infantil, 
o ensino fundamental e o ensino médio; e o segundo nível está composto pela educação superior. A partir dessa lei, muda-se a nomenclatura acerca dos níveis de ensino, ou seja, os chamados $1^{\circ}$ e $2^{\circ}$ graus passam a ser chamados de Ensinos Fundamental e Médio.

Como se pode perceber, a educação fica dividida em básica e superior, todavia, a educação profissionalizante não se enquadra em nenhum desses dois níveis, cabendo à educação básica, segundo o artigo 22 da LDB, assegurar a formação comum para o exercício da cidadania, além de fornecer meios para a progressão nos trabalhos e nos posteriores estudos. "Dito de outra maneira, a educação profissional não faz parte da estrutura da educação regular brasileira. É considerada como algo que vem em paralelo ou como um apêndice" (MOURA; GARCIA; RAMOS, 2007, p. 17).

Isso se confirma no Capítulo III, do artigo 40, da LDB, quando afiança que "a educação profissional será desenvolvida em articulação com o ensino regular ou por diferentes estratégias de educação continuada, em instituições especializadas ou no ambiente de trabalho".

Vale ressaltar que essa resolução era objeto do Projeto de Lei (PL) 1.603, de iniciativa do poder executivo. Grande parte do conteúdo desse PL, inclusive no tocante à separação dos ensinos médio e profissionalizante, foi contemplada no Decreto 2.208, de 17 de abril de 1997, que, por sua vez, foi revogado pelo Decreto 5.154, de 23 de julho de 2004.

Uma das determinações do Decreto 5.154/04 é que o estudante poderia ter, concomitantemente, a oferta de ensino médio e profissionalizante, em instituições diferentes, ou não, sob a condição de matrículas distintas para cada curso. Caracterizava-se, neste momento, a privatização da oferta do ensino médio de cunho profissionalizante, mas, em contrapartida, o crescimento da formação técnica na Rede Federal.

Cabia ao Programa de Expansão da Educação Profissional (PROEP), a estruturação da Rede Federal, sob a compreensão de torná-la competitiva para o mercado de trabalho, uma vez que era necessário que a rede estivesse preparada para vender seus cursos à sociedade, a fim de melhorar parte do seu orçamento.

Vale ressaltar que, de modo algum, as instituições poderiam apresentar alguma proposta que mantivesse relação com a oferta de ensino médio, sob pena de afastamento definitivo das instituições federais de educação tecnológica, "[...] a idéia era extinguir definitivamente a vinculação das instituições federais de educação tecnológica com a educação básica” (MOURA; GARCIA; RAMOS, 2007, p. 20).

Na tentativa de mudar essa realidade, o Decreto 5.154/04 traz de volta a possibilidade de integrar a educação profissionalizante ao ensino médio, desde que sejam matrículas diferentes, como apontado anteriormente. 0 que contribuiu para o crescimento do número de instituições particulares que ofertam cursos técnicos profissionalizantes, conforme demonstrado no quadro a seguir.

Quadro 1 - Evolução do número de matrículas na educação profissional por dependência administrativa - Brasil - 2008/2014

\begin{tabular}{|c|c|c|c|c|c|}
\hline \multirow{2}{*}{ Ano } & \multicolumn{4}{|c|}{ Número de matrículas na Educação Profissional por dependência administrativa. } \\
\cline { 2 - 6 } & Total & Federal & Estadual & Municipal & Privada \\
\hline 2008 & 942.917 & 132.732 & 322.362 & 36.120 & 451.703 \\
\hline 2010 & 1.178 .540 & 179.433 & 418.157 & 32.265 & 548.685 \\
\hline
\end{tabular}




\begin{tabular}{|c|c|c|c|c|c|}
\hline \multirow{2}{*}{ Ano } & \multicolumn{5}{|c|}{ Número de matrículas na Educação Profissional por dependência administrativa. } \\
\cline { 2 - 6 } & Total & Federal & Estadual & Municipal & Privada \\
\hline 2012 & 1.398 .173 & 224.892 & 505.714 & 31.056 & 636.531 \\
\hline 2014 & 1.784 .403 & 249.604 & 536.678 & 40.927 & 957.194 \\
\hline
\end{tabular}

Fonte: Censo 2015 da Educação Profissional. Disponível em http://portal.mec.gov.br/index.php?option=com_docman\&view=download\&alias=17044-dados-censo-2015-11-02materia\&ltemid=30192. Acesso em: 30 ago. 2018

Ao analisar o quadro acima, percebe-se que o crescimento do número de matrículas para cursos profissionalizantes foi sobremodo elevado nas instituições particulares, representando $111,9 \%$ das matrículas no País. Contudo, esse crescimento não está limitado apenas à oferta de cursos de nível técnico, mas também, e principalmente, de cursos de nível superior.

Em 2008, segundo o Instituto de Pesquisa Econômica Aplicada (IPEA), houve maior investimento em Educação Profissional Tecnológica (EPT) com a aprovação de Lei 11.892, de 29 de dezembro de 2008, que cria os Institutos Federais de Educação Ciência e Tecnologia (IF). Segundo o Mapa da Educação Profissional e Tecnológica, as principais iniciativas desenvolvidas nesse período foram:

[...] a criação do programa Brasil Profissionalizado (decreto 6.302/2007); a criação da rede de ensino técnico à distância - Rede e-Tec Brasil (decreto 6.301/2007); o Acordo de Gratuidade com os Serviços Nacionais de Aprendizagem (decretos 6.633/2008, 6.635/2008, 6.632/2008 e 6.637/2008), e a criação do Sistema Nacional de Informações da Educação Profissional e Tecnológica (Sistec), também em 2008 (MEPT, 2015, p. 84).

Nesse mesmo ano, buscando dar continuidade à política de sistematização e organização da oferta dos cursos técnicos no País, o Ministério da Educação (MEC), por meio da Secretaria de Educação Profissional e Tecnológica (SETEC), lançou o Catálogo Nacional de Cursos Técnicos (CNCT), que tem como objetivo apresentar aos estudantes; às escolas e à sociedade os cursos técnicos de nível médio em desenvolvimento no país. Na edição lançada do catálogo, em 2014, buscou-se incluir novos cursos ofertados, que surgiram a partir da demanda da evolução econômica, tecnológica e social do país.

Diante desse cenário de investimentos, Moura, Garcia e Ramos (2007) fazem uma reflexão:

Para que a integração entre a educação profissional técnica de nível médio e o ensino médio constitua-se em política pública educacional é necessário que essa assuma uma amplitude nacional na perspectiva de que as ações realizadas nesse âmbito possam enraizar-se em todo o território brasileiro. (MOURA; GARCIA; RAMOS, 2007, p. 27). 
Por isso, à medida que crescia a oferta, aumentava-se a procura. Para tanto, o Governo Federal,além do lançamento do CNCT, investiu em programas de qualificação profissional ${ }^{3}$, como o Brasil Profissionalizado, o Programa Nacional de Acesso ao Ensino Técnico e ao Emprego (PRONATEC), o Programa Mulheres Mil etc., que eram oferecidos pelos Institutos Federais.

É importante salientar que também há investimentos do governo na oferta de vagas em programas da inciativa privada, como, por exemplo, os cursos técnicos profissionalizantes oferecidos pelo Serviço Nacional de Aprendizagem Industrial (SENAI) e pelo Serviço Nacional de Aprendizagem Comercial (SENAC).

Sempre com o objetivo de alcançar um número cada vez maior de alunos, e, como já citado, buscando alcançar essa amplitude nacional e enraizamento de suas ações no território brasileiro, uma das estratégias do governo foi a oferta desses cursos na modalidade a distância.

Assim, seria possível auferir um quantitativo ainda maior de candidatos aos cursos, uma vez que é uma modalidade de ensino mais facilmente adequada à realidade do seu público alvo, ou seja, pessoas que têm interesse em qualificar-se profissionalmente, mas não dispõem de tempo suficiente para estarem diariamente em uma sala de aula na busca dessa qualificação.

\section{AS CONTRIBUIÇÕES DA EAD NA FORMAÇÃO TÉCNICA DE NÍVEL MÉDIO}

As bases legais da Educação a Distância (EAD) estão amparadas na LDB, Lei 9.394, de 20 de dezembro de 1996. Com esta lei, a EAD passa a ser entendida como "[...] modalidade plenamente integrada ao sistema de ensino" (DIAS; LEITE, 2010, p. 17).

0 artigo 80, da LDB, preconiza que o poder público deve incentivar o desenvolvimento e a veiculação da modalidade, em qualquer nível de ensino. Para tanto, ele alerta que a EAD deve ser organizada com abertura e regime especiais, e será oferecida por instituições especificamente credenciadas pela União.

A LDB também estabelece que o Ministério da Educação e Cultura (MEC) é responsável pelo credenciamento das instituições, além de estabelecer alguns requisitos na realização de provas e no registro de certificação relativa aos cursos que abordam a metodologia usada na modalidade de educação a distância. Parafraseando Dias e Leite (2010, p. 17): "Percebe-se na LDB um esforço em redescobrir a relevância social dos sistemas de EAD".

Vale também, concordando com a afirmativa destas autoras, no que diz respeito ao esforço do governo em relação à relevância da modalidade a distância, citar o Decreto 5.622, de 19 de dezembro de 2005 como um dos principais contributos do governo. Em seu Artigo $1^{\circ}$, esse Decreto estabelece que:

$\S 1^{\circ} \mathrm{A}$ educação a distância organiza-se segundo metodologia, gestão e avaliação peculiares, para as quais deverá estar prevista a obrigatoriedade de momentos presenciais para: - avaliações de estudantes;

- estágios obrigatórios, quando previstos na legislação pertinente;

3 Maiores informações acerca dos programas de qualificação do Governo Federal estão disponíveis no site: http://www. observatoriodopne.org.br/metas-pne/11-educacao-profissional 
- defesa de trabalhos de conclusão de curso, quando previstos na legislação pertinente; e - atividades relacionadas a laboratórios de ensino, quando for o caso.

Desta maneira, para que a educação a distância se torne um processo factível e coeso, legitimado por lei, é necessário que esses pré-requisitos sejam respeitados, principalmente no tocante aos momentos presenciais, que são, demasiadamente, importantes durante a avaliação dos alunos e na execução das atividades relacionadas ao processo educacional, além de, em casos específicos, na realização de estágios supervisionados.

Em relação a isso, Dias e Leite (2010) enfatizam que com a produção desses momentos presenciais há como mensurar o nível de aprendizagem do alunado. Sem eles, o processo de ensino e aprendizagem na referida modalidade pode ficar comprometido.

Ainda fazendo menção ao Decreto 5.622/05, seu artigo $2^{\circ}$ estabelece que a Educação a Distância também pode ser ofertada na educação profissionalizante, desde que abranja cursos técnicos de nível médio, tecnólogos de nível superior, além da educação superior, alcançando assim os níveis de graduação e especialização Lato Sensu e Strictu Sensu.

É importante salientar que os cursos de cunho profissionalizante estão subordinados ao Conselho Nacional de Educação (CNE), do qual depende a sua aprovação, contudo, no tocante aos cursos de especialização strictu sensu, é necessário também que estejam fundamentados em relatórios da Coordenação de Aperfeiçoamento de Pessoal de Nível Superior (CAPES).

0 crescimento da modalidade EAD, nesse segmento de ensino, trouxe grandes avanços. Nesse sentido, vale ressaltar que o Censo 2015 da Educação Profissionalizante afirma que houve evolução do número de matriculas na educação profissional por dependência administrativa no período de 2008 a 2014.

Das 957.194 (novecentos e cinquenta e sete mil, cento e noventa e quatro) matrículas de ensino técnico profissional, ilustradas no Quadro 1, grande parte dessas matrículas pertence à graduação, contudo, não se pode desenvencilhar a participação da formação de nível médio. O que corrobora com os dados apresentados pelo Censo da EAD de 2015, quando afirma que foram ofertados 219 cursos de nível técnico profissionalizante diferentes, na modalidade.

É também importante salientar que o Plano Nacional da Educação (PNE, on-line), sancionado pelo Congresso Federal, em 2014, pretende triplicar o número de matrículas no ensino técnico profissionalizante até o ano de 2024.

Segundo este documento, em 2016 foram abertas 1.775 .324 (um milhão, setecentos e setenta e cinco mil, trezentos e vinte e quatro) matrículas para o ensino técnico profissionalizante, e a meta para 2014 é chegar a 5.224.584 (cinco milhões, duzentos e vinte e quatro mil, quinhentos e oitenta e quatro) novas matrículas. Além de quase triplicar o número de matrículas, o PNE busca também assegurar, até 2024 , que $50 \%$ da oferta desses cursos sejam destinados a estudantes da rede pública.

Um dos principais papéis da educação a distância é garantir o cumprimento de políticas públicas que incluam todo aquele que manifestar interesse em adentrar ao mundo da educação virtual, como, por exemplo, as pessoas que não residem em grandes centros urbanos, ou ainda os que trabalham grande parte do dia e não têm condições de estudar sem que haja a flexibilidade de horários que é peculiar a esta modalidade de ensino. 
Acrescenta-se, também, a este público, pessoas que não estão mais na faixa etária correspondente a determinado período escolar. Por não se sentirem confortáveis em estar numa sala de aula com pessoas com idades inferiores, veem na EAD uma possibilidade de concluir essa etapa da vida, capacitar-se para o mercado de trabalho, fazendo de uma forma que não atrapalhe seus afazeres diários.

A EAD quebra as barreiras espaço-temporais, abre novos paradigmas para a escola e ainda amplia as perspectivas dos estudantes que aguardavam por uma oportunidade de estudar na busca por melhores condições de vida. Essa busca por melhores condições de vida, para muitos alunos, inclui a formação técnica profissionalizante, desde os estudantes que fazem um curso integrado à educação básica, àqueles que voltam à escola depois de muito tempo fora dela.

É importante frisar que um desempregado, sem formação específica, leva, em média, de 1,5 a 2 anos para ser realocado ao mercado, e, com a crise financeira que o Brasil enfrenta há alguns anos, esse período pode ser ainda maior; no entanto, aos que possuem formação técnica profissionalizante, o tempo de realocação cai para seis meses, em média.

Percebe-se, com isso, que a capacitação para o mercado de trabalho em menor espaço de tempo, aumenta as chances do indivíduo em uma nova contratação, ou realocação, e diminui esse período de transição.

E se essa formação for nos moldes da educação a distância, até os investimentos serão menores, levando-se em consideração que, para cursos da iniciativa privada, as mensalidades têm valores inferiores aos cobrados no ensino presencial, além disso, também serão reduzidos os gastos com transporte e alimentação, uma vez que, para os cursos que são ofertados sob a metodologia totalmente a distância, os encontros acontecem apenas uma vez por semana.

Nesse prisma, Amorim (2012, p. 4) ressalta que

[...] a minimização do deslocamento gerando a economia de tempo e dinheiro, o ensino independente onde tempo e lugar são administrados pelos alunos de acordo com seu ritmo, podendo gerenciar seu processo de ensino-aprendizagem [...] são alguns pontos positivos ao se fazer EAD, inclusive na formação técnica.

Essa minimização de deslocamento, a economia financeira e a autonomia do aluno faz da EAD uma forte aliada no processo de profissionalização, contratação e realocação ao mercado de trabalho, por isso a modalidade a distância se torna relevante para o avanço dos cursos e o surgimento de outros, seja de graduação ou de nível técnico, visto que cresce a oferta e a demanda por cursos nesta modalidade.

\section{CONSIDERAÇÕES FINAIS}

A Educação a Distância pode ser entendida como instrumento, altamente significativo, de contribuição para alcançar um contingente cada vez maior de pessoas, com igualdade de condições e é compreendida como instrumento de qualificação significativo e abrangente, permitindo a formação inicial e continuada de profissionais ou aspirantes a profissionais. 
Aliada à formação técnica profissionalizante, é possível depreender que essa união está contribuindo para a diminuição do índice de desemprego, uma vez que inclui, ou reinclui, algumas dessas pessoas ao mercado de trabalho.

Nesse sentido, a formação técnica representa um saldo altamente positivo e mostra que as empresas estão buscando habilidades do profissional e não apenas conhecimento técnico.

Com vistas aos desafios de uma sociedade moderna e tecnológica, além da relevância da educação a distância na formação técnica profissionalizante, tendo em vista que os cursos de nível técnico preparam seus alunos em menor espaço de tempo, se comparado aos de nível superior, com investimento financeiro bem menor, conclui-se que a educação a distância tornou-se grande aliada no processo de formação técnica profissionalizante dos estudantes brasileiros.

\section{REFERÊNCIAS}

ABED - Associação Brasileira de Educação a Distância. Censo EAD.BR: Relatório Analítico da Aprendizagem a Distância no Brasil 2014. FGV On-line, Curitiba: Ibpex, 2017.

BRASIL, Câmara dos Deputados. Lei n⿳0 4.024, de 20 de dezembro de 1961. Fixa as Diretrizes e Bases da Educação Nacional. Disponível em: http://www2.camara.leg. br/legin/fed/lei/1960-1969/ lei-4024-20-dezembro-1961-353722-normaatualizada-pl.p df. Acesso em: 31 jul. 2018.

BRASIL, Presidência da República, Subchefia para Assuntos Jurídicos, Lei n0 5.692, de 11 de agosto de 1971. Disponível em: http://www.planalto.gov.br/ccivil_03/Leis/L56 92.htm. Acesso em: 25 jul. 2018.

BRASIL, Presidência da República, Subchefia para Assuntos Jurídicos, Lei nº 9.394, de 20 de dezembro de 1996. Disponível em: http://www.planalto.gov.br/ccvil_03/ leis/L9394.htm. Acesso em: 18 ago. 2018.

BRASIL, Presidência da República, Subchefia para Assuntos Jurídicos, Decreto nº 2.208, de 17 de abril de 1997. Disponível em: http://www.planalto.gov.br/ccivil_03/de creto/D2208.htm.

Acesso em: 26 ago. 2018.

BRASIL, Diretrizes Curriculares Nacionais para a Educação Profissional de Nível Técnico. Parecer 16, de 5 de outubro de 1999. Disponível em: http://portal. mec.gov.br/ setec/arquivos/pdf/PCNE_ CEB16_99.pdf. Acesso em: 15 ago. 2018.

BRASIL, Presidência da República, Subchefia para Assuntos Jurídicos, Decreto n⿳0 5.154, de 23 de julho de 2004. Disponível em: http://www.planalto.gov.br/ccvil_03/_ato2004-2006/2004/decreto/ d5154.htm. Acesso em: 15 ago. 2018. 
BRASIL. Ministério do Planejamento, Orçamento e Gestão. Instituto Brasileiro de Geografia e Estatística.

Pesquisa Nacional por Amostragem de Domicílios. 2014. Disponível em: ftp://ftp. ibge.gov.br/

Estimativas_de_Populacao/Estimativas_2014/est imativa_dou_2014.pdf. Acesso em: 28 ago. 2018.

BRASIL, Ministério da Educação. Mapa da Educação Profissional e Tecnológica: experiências internacionais e dinâmicas regionais brasileiras. - Brasília, DF. Centro de Gestão e Estudos Estratégicos, 2015. Disponível em: http://portal.mec.gov.br/ind ex.php?option=com_ docman\&view=download\&alias=36781-a-contribuicao-pronatec-expansao-educacao-profibrasileira-pdf\&ltemid=30192. Acesso em: 1 set. 2018.

BRASIL. Ministério do Planejamento, Orçamento e Gestão. Instituto Brasileiro de Geografia e Estatística. Educação e qualificação profissional: 2014. Coordenação de Trabalho e Rendimento, Rio de Janeiro, IBGE, 2017. Disponível em: https://bibliot eca.ibge.gov.br/visualizacao/livros/ liv100061.pdf. Acesso em: 1 set. 2018.

DIAS, Rosilâna Aparecida; LEITE, Lígia Silva. Educação a distância: da legislação ao pedagógico. 2. ed. Petrópolis, RJ: Vozes, 2010.

GARCIA, Sandra Regina de oliveira. O fio da história: a gênese da formação profissional no Brasi”. In: Trabalho e Crítica, São Leopoldo: Ed. UNISINOS, 2000.

MIMESSE, Eliane. 0 ensino profissional obrigatório de $2^{\circ}$ grau nas décadas de 70 e 80 e as aulas dos professores de história. Revista HISTEDBR, on-line, Campinas, n. 26, p. 105-113, jun. 2007. Disponível em: http://www.histedbr.fe.unicam p.br/revista/edicoes/26/art06_26.pdf. Acesso em: 20 ago. 2018.

MOURA, Dante Henrique; GARCIA, Sandra Regina de Oliveira; RAMOS, Marise Nogueira. Educação profissional técnica de nível médio integrada ao ensino médio. Documento Base, Brasília, 2007. Disponível em: http://portal.mec.gov.br/setec/arquivos/pdf/documento_base.pdf. Acesso em: 1 ago. 2018.

O PNE - Plano Nacional de Educação. 0 Observatório. Disponível em: http://www. observatoriodopne.org.br/metas-pne/11-educacao-profissional. Acesso em: 24 ago. 2018 


\section{Como citar este artigo:}

ROMEO, Andrea. Lo special account del fenomeno religioso nel dibattito nordamericano. Argumenta Journal Law, Jacarezinho - PR, Brasil, n. 29., 2018, p. 15-48. DOI: $10.17564 / 2316-3828.2018 v 7 n 1 p 13-24$

\section{(C) (1) (2)}

Este artigo é licenciado na modalidade acesso abertosob a Atribuição-Compartilhalgual CC BY-SA

1 Pegagoga; Doutora e Mestra em Educação, Área de Concentração: Educação e Tecnologia, Educação a Distância, Formação Docente. E-mail: andreaknunes@gmail.com

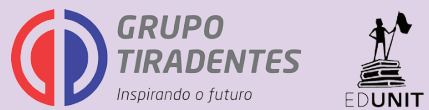


